\title{
Comunicação \\ Dessecação Química em Pré-Colheita da Mamona
}

\author{
José Salvador Simoneti Foloni ${ }^{1}$, Andréia Cristina Silva Hirata², Daniel Neco Pereira ${ }^{3}$, \\ Marcio Luiz Martins de Carvalho ${ }^{3}$, Diego Casavechia ${ }^{3}$
}

\section{RESUMO}

A mamona (Ricinus communis) tem hábito de crescimento indeterminado, com expressiva desuniformidade de maturação dos grãos, o que dificulta sobremaneira a colheita mecanizada. O objetivo deste trabalho foi avaliar a eficiência do herbicida glifosato, isolado, ou, em mistura com 2,4-D, e também do paraquat, na dessecação em précolheita da mamona. Foram realizados dois experimentos de campo, no delineamento em blocos ao acaso, com quatro repetições, em Rancharia-SP, de março a setembro de 2005. No experimento 1, avaliou-se a mistura de doses de 2,4-D e de glifosato, e no experimento 2 a dessecação somente com paraquat. Foi determinado o teor de água da parte aérea de plantas de mamona em diferentes dias após a aplicação (DAA). A dessecação da mamona com a mistura de 2,4-D e glifosato tem efeito somente a partir de 20 DAA. O 2,4-D aplicado isoladamente tem expressiva capacidade de desidratação do dossel vegetal, porém, inferior à da mistura de 2,4-D e glifosato. A melhor dessecação é com 1,34 $\mathrm{kg}$ ha-1 $\mathrm{de}^{-2,4-}$ D mais $1,42 \mathrm{~kg} \mathrm{ha}^{-1}$ de glifosato. A dose de $1,2 \mathrm{~kg} \mathrm{ha}^{-1}$ de paraquat reduz expressivamente o teor de água das plantas da mamona, porém, com desempenho inferior ao da mistura de 2,4-D e glifosato.

Palavras-chave: Ricinus communis, paraquat, glifosato, 2,4-D, herbicidas dessecantes.

\begin{abstract}
\section{Chemical pre-harvest desiccation in castor bean}

The castor bean has indeterminate growth habit and non-uniformity of grain maturation at harvest. However, preharvest desiccant application can increase the efficiency of mechanized harvesting. The objective of this work was to evaluate effects of the herbicides glyphosate alone or mixed with 2,4-D, and paraquat alone, in pre-harvest desiccation of castor bean. The field experiments were arranged in a completely randomized design, with four replications, in Rancharia, São Paulo State, from March to September 2005. The experiment one evaluated the application of two doses of 2,4-D associated with four doses of glyphosate at 10, 20 and 30 days after application (DAA). The experiment two evaluated four doses of paraquat at 30 DAA. The pre-harvest desiccation of castor bean with 2,4-D + glyphosate showed effect only from 20 DAA. The 2,4-D applied alone provided significant dehydration of the plant, however, the effect was lower than the mixture 2,4-D + glyphosate. The best pre-harvest desiccation in castor bean was obtained with $1.34 \mathrm{~kg}$ 2,4-D ha ${ }^{-1}$ plus $1.42 \mathrm{~kg}_{\text {glyphosate }} \mathrm{ha}^{-1}$. The dose $1.2 \mathrm{~kg}$ paraquat ha-1 significantly reduced moisture in castor bean, however, it was less efficiently than the mixture 2,4-D + glyphosate.
\end{abstract}

Key words: Ricinus communis L., desiccant herbicides, glyphosate, 2,4-D, paraquat.

\footnotetext{
Recebido para publicação em 01/06/2010 e aprovado em 22/07/2011

(1) Engenheiro-Agrônomo, Doutor. Área de Manejo do Solo e da Cultura, Embrapa Soja, Rod. Carlos João Strass, Acesso Orlando Amaral, Caixa Postal 231, 86001-970, LondrinaPR, Brasil. salvador.foloni@cnpso.embrapa.br

(2) Engenheira-Agrônoma, Doutora. Área de Fitotecnia, Apta - Pólo Alta Sorocabana, Rod. Raposo Tavares, Km 561, Caixa Postal 298, 19015-970, Presidente Prudente-SP, Brasil. andreiacs@apta.sp.gov.br

(3) Engenheiros Agrônomos. Centro de Ciências Agrárias, Universidade do Oeste Paulista. Rod. Raposo Tavares, Km 572, 19067-175, Presidente Prudente-SP, Brasil.
} 


\section{INTRODUÇÃO}

Um dos entraves à mecanização da colheita da mamona (Ricinus communis) é o seu hábito de crescimento indeterminado, com florescimento do tipo simpodial, ou seja, há formação de estruturas vegetativas simultaneamente ao florescimento e frutificação. Portanto, não há sincronia de maturação entre os diferentes cachos da mamona. Além disso, dependendo das condições edafoclimáticas, fitossanitárias e de manejo, essa oleaginosa pode assumir comportamento de espécie perene (Savy Filho, 2005).

A utilização de herbicidas dessecantes pode tornar a colheita mecanizada da mamona mais eficiente, e tal procedimento tem sido consideravelmente estudado para diferentes culturas anuais, como por exemplo, para a soja (Almeida et al., 1991), girassol (Vidal \& Fleck, 1993) e feijão (Domingos et al., 1997).

Agricultores procedem à dessecação em pré-colheita de lavouras com a finalidade de forçar a desfolha e, ou, controlar plantas daninhas. Esse procedimento permite a antecipação da colheita, facilita o trabalho do maquinário, pode minimizar prejuízos decorrentes de ataques de fungos e pragas no final da cultura (Almeida et al., 1991; Domingos et al., 1997), e pode reduzir problemas ocasionados pela maturação desuniforme de estruturas reprodutivas (Roman et al., 2001).

O paraquat tem sido amplamente utilizado para dessecação em pré-colheita de diversas culturas, e é classificado como herbicida de contato. Este dessecante químico possui a capacidade de captar elétrons provenientes da fotossíntese e formar radicais livres, e em poucas horas após a sua aplicação, na presença de luz, promove severas lesões em tecidos fotossinteticamente ativos (Rodrigues \& Almeida, 2005).

O glifosato está entre os principais herbicidas utilizados para dessecação no sistema plantio direto (SPD). Ele é sistêmico, não seletivo e o seu mecanismo de ação baseia-se na interrupção da rota do ácido chiquímico, responsável pela produção de aminoácidos aromáticos essenciais para a síntese de proteínas e divisão celular nas regiões meristemáticas da planta (Hess, 1994). Este herbicida também é muito utilizado em mistura com 2,4-D, como por exemplo, para a dessecação em pré-semeadura no SPD, com o objetivo de ampliar o espectro de controle de espécies de plantas daninhas, principalmente latifoliadas (Ramos \& Durigan, 1996; Santos et al., 2002).

De acordo com informações recorrentes sobre a cultura da mamona (Savy Filho, 2005), a dessecação em précolheita seria justificável em razão dos seguintes argumentos: (1) os grãos não são utilizados para alimentação humana e animal; (2) há expressiva desuniformidade de maturação das estruturas reprodutivas; (3) é economica- mente viável encerrar o cultivo após a maturação dos cachos terciários, para lavouras de ciclo anual; (4) após a colheita, as soqueiras podem rebrotar e competir com a cultura subsequente.

O objetivo deste trabalho foi avaliar a eficiência do herbicida glifosato, isolado ou em mistura com 2,4-D, e, também, do paraquat, na dessecação em pré-colheita do cultivar de mamona AL Guarany 2002, conduzido como lavoura de safrinha em sucessão à soja no SPD.

\section{MATERIAL E MÉTODOS}

O trabalho foi realizado em Rancharia-SP, entre março a setembro de 2005 , em área experimental a $22^{\circ} 14^{\prime} 23^{\prime \prime} \mathrm{S}$, $50^{\circ} 57^{\prime} 53^{\prime \prime} \mathrm{W}$ e $421 \mathrm{~m}$ de altitude. O solo foi classificado como Latossolo Vermelho distroférrico (Embrapa, 1999), de textura média ( $245 \mathrm{~g} \mathrm{~kg}^{-1}$ de argila, $95 \mathrm{~g} \mathrm{~kg}^{-1}$ de silte e $660 \mathrm{~g} \mathrm{~kg}^{-1}$ de areia), manejado no SPD por cinco anos consecutivos antes da instalação do experimento. Foram feitas amostragens do solo na profundidade de 0 a $20 \mathrm{~cm}$, para caracterizar atributos químicos (Raij et al., 2001), obtendo-se os seguintes valores: $\mathrm{pH}\left(\mathrm{CaCl}_{2} 1 \mathrm{~mol} \mathrm{~L}^{-1}\right)$ 5,9; $26 \mathrm{~g} \mathrm{dm}^{-3}$ de M.O.; $12 \mathrm{mg} \mathrm{dm}^{-3}$ de Presina; $22 \mathrm{mmol}_{\mathrm{c}} \mathrm{dm}^{-3}$ de $\mathrm{H}+\mathrm{Al} ; 2,1 \mathrm{mmol}_{\mathrm{c}} \mathrm{dm}^{-3} \mathrm{de} \mathrm{K} ; 34 \mathrm{mmol}_{\mathrm{c}} \mathrm{dm}^{-3} \mathrm{de} \mathrm{Ca} ; 11$ $\mathrm{mmol}_{\mathrm{c}} \mathrm{dm}^{-3} \mathrm{de} \mathrm{Mg} ; 47,1 \mathrm{mmol}_{\mathrm{c}} \mathrm{dm}^{-3}$ de SB; 69,1 $\mathrm{mmol}_{\mathrm{c}}$ $\mathrm{dm}^{-3}$ de CTC; 68,18 \% de saturação por bases (V).

A semeadura da mamona (Ricinus communis L.), cultivar AL Guarany 2002, foi realizada na segunda semana de março de 2005, no ambiente definido tecnicamente como safrinha, sobre a palhada de soja no SPD. Utilizaram-se $300 \mathrm{~kg} \mathrm{ha}^{-1}$ de fertilizante formulado NPK 05-25-10 na semeadura, espaçamento entrelinhas de $0,90 \mathrm{~m}$, e na adubação de cobertura, feita aos 40 dias após a emergência da cultura (40 DAE), foram aplicados $30 \mathrm{~kg} \mathrm{ha}^{-1}$ de $\mathrm{N}$ com a fonte sulfato de amônio, a partir de recomendações de Savy Filho (2005).

Aos 135 DAE, foram feitas medições em seis metros contíguos de linha de semeadura, em quatro pontos ao acaso, em faixas de lavoura adjacentes às parcelas experimentais, com os seguintes valores: densidade populacional final de 13.706 plantas ha ${ }^{-1}( \pm 898)$; altura de inserção dos cachos primários até a superfície do solo de 70,72 cm $( \pm 18,30)$; altura de inserção dos cachos secundários de $114,13 \mathrm{~cm}( \pm 27,88)$; altura de inserção dos cachos terciários de $138,23 \mathrm{~cm}$ ( $\pm 29,58)$; diâmetro médio dos caules no meio do segundo internódio, de $3,29 \mathrm{~cm}( \pm 0,38)$.

Foram instalados dois experimentos no mesmo dia, nas mesmas condições ambientais e de manejo. No experimento 1, para estudar a associação de glifosato e 2,4-D, utilizou-se o delineamento experimental em blocos completos casualizados, com quatro repetições, no esquema fatorial $2 \times 4$, com parcelas subdivididas, da seguinte forma: nas parcelas foram alocadas duas doses de 0 e $1,34 \mathrm{~kg}$ 
ha $^{-1}$ de 2,4-D, em interação com quatro doses de $0,0,72$, 1,44 e 2,16 $\mathrm{kg} \mathrm{ha}^{-1}$ do equivalente ácido de glifosato e nas subparcelas, foram três épocas de amostragem de plantas, aos 10, 20 e 30 dias após a aplicação dos herbicidas (DAA).

No experimento 2, para estudar a dessecação somente pelo paraquat, também utilizou-se o delineamento experimental em blocos completos casualizados, com quatro repetições, com os seguintes tratamentos: quatro doses de $0,0,4,0,8$ e 1,2 $\mathrm{kg} \mathrm{ha}^{-1}$ de paraquat.

As subparcelas foram constituídas de seis linhas de semeadura de mamona, com $3 \mathrm{~m}$ de comprimento cada, sendo a área útil composta por $2 \mathrm{~m}$ contíguos nas quatro linhas centrais, desconsiderando-se $1 \mathrm{~m}$ de bordadura em cada extremidade. As aplicações dos herbicidas foram feitas com pulverizador manual pressurizado a $\mathrm{CO}_{2}$, equipado com barra contendo duas ponteiras TT 110.02 espaçadas a $0,50 \mathrm{~m}$, posicionadas a aproximadamente $0,50 \mathrm{~m}$ acima do dossel vegetal, operando à pressão constante de $150 \mathrm{kPa}$, com consumo de calda da ordem de $300 \mathrm{~L} \mathrm{ha}^{-1}$.

No dia da aplicação dos tratamentos experimentais, foram feitas coletas dos cachos primários, secundários e terciários de todas as plantas contidas em quatro metros contíguos de linha de semeadura, em quatro pontos ao acaso, em faixas de lavoura adjacentes às parcelas experimentais, para caracterização do conteúdo de água dos grãos e da produtividade da cultura. Os grãos foram trilhados manualmente e os teores de água foram determinados pelo método da estufa, a $105{ }^{\circ} \mathrm{C}$ por 24 horas, e no cálculo da produtividade corrigiu-se a umidade para $13 \%$, com os seguintes valores: $56,10 \mathrm{~g} \mathrm{~kg}^{-1}( \pm 3,76)$ de água nos grãos dos cachos primários; 88,40 $\mathrm{g} \mathrm{kg}^{-1}( \pm 6,67)$ de água nos grãos dos cachos secundários; $111,30 \mathrm{~g} \mathrm{~kg}^{-1}$ ( \pm $9,35)$ de água nos grãos dos cachos terciários; e produtividade média de grãos de mamona de $1.767,50 \mathrm{~kg} \mathrm{ha}^{-1}( \pm$ 212,20). A lavoura de mamona foi submetida aos tratamentos de dessecação em pré-colheita no estádio de maturação dos cachos terciários, definido a partir de avaliação visual, seguindo as recomendações de viabilidade econômica para essa oleaginosa em cultivos de ciclo anual (Savy Filho, 2005).

No experimento 1, as amostragens das plantas de mamoneira para determinação do teor de água da parte aérea foram realizadas aos 10, 20 e 30 DAA, de acordo com o delineamento supracitado. No experimento 2, as amostragens foram realizadas somente aos 30 DAA. Foi coletada a parte aérea das plantas, cortada rente à superfície do solo, de toda a área útil de cada subparcela experimental, com $1 \mathrm{~m}$ de bordadura entre as épocas de coleta. Os caules, ramos, folhas e frutificações amostrados foram picados manualmente e acondicionados, imediatamente após o corte, em sacos de plástico vedados. Em seguida, os fragmentos de todo o dossel vegetal foram homoge- neizados e quatro alíquotas de aproximadamente $1 \mathrm{~kg}$ foram retiradas, por subparcela, para pesagem verde (massa da matéria fresca), secagem em estufa de aeração forçada, a $60{ }^{\circ} \mathrm{C}$, por 72 horas, e pesagem da matéria seca para determinação dos teores de água.

Para o experimento 1 , foram considerados como variáveis qualitativas os tratamentos de 2,4-D, os quais foram submetidos à análise de variância $(\mathrm{p}<0,05)$ e teste Tukey $(\mathrm{p}<0,05)$. Para as doses de glifosato em interação com o 2,4-D, fez-se análise de regressão, na qual foram escolhidas equações a partir da significância do coeficiente de regressão e do teste $\mathrm{F}$ da regressão (ambos a 5\% de probabilidade), em consonância com os maiores coeficientes de determinação $\left(\mathrm{R}^{2}\right)$. No experimento 2, aplicou-se também a análise de regressão com os mesmos procedimentos.

\section{RESULTADOS E DISCUSSÃO}

Aos 10 dias após a aplicação dos herbicidas glifosato e 2,4-D (10 DAA), não foi observado efeito da dessecação sobre o teor de água do dossel da mamona (Figura 1-a). Portanto, independentemente do herbicida e da dose utilizada, a desidratação efetiva da parte aérea do cultivar AL Guarany 2002, no ambiente de safrinha no oeste do Estado de São Paulo, foi detectável somente aos 20 DAA, evidenciando a capacidade dessa oleaginosa em se manter hidratada no curto prazo.

$\mathrm{Na}$ avaliação feita aos 20 DAA, a combinação de 2,4$\mathrm{D}$ e glifosato proporcionou avanço significativo na perda de água do dossel vegetal, em comparação à dessecação feita somente com glifosato (Figura 1-b). Esse resultado pode ser explicado pelo fato de as gramíneas serem o alvo principal do glifosato, ao contrário do 2,4$\mathrm{D}$, que é mais eficiente no controle de latifoliadas, isoladamente ou em misturas. Nas dicotiledôneas, a auxina sintética não é metabolizada tão rapidamente quanto a auxina endógena, enquanto as monocotiledôneas (gramíneas) podem rapidamente inativar auxinas sintéticas (Taiz \& Zeiger, 2004).

Aos 20 DAA, a adição de 2,4-D na calda de pulverização proporcionou resposta linear negativa para a perda de água do dossel vegetal, em combinação com doses de glifosato, seguindo a mesma tendência de resposta linear observada para a dessecação feita somente com glifosato (Figura 1-b). Aos 30 DAA, a mistura de 2,4-D e glifosato levou ao ajuste quadrático para a perda de água das plantas de mamona, evidenciando que a associação de herbicidas permite reduzir a dose de glifosato (Figura 1-c).

O 2,4-D proporcionou forte perda de água da mamona, mesmo quando foi aplicado isoladamente, tanto aos 20, como aos 30 DAA (Figuras 1-b e 1-c), confirmando a argumentação de Azevedo \& Severino (2006), de que essa 

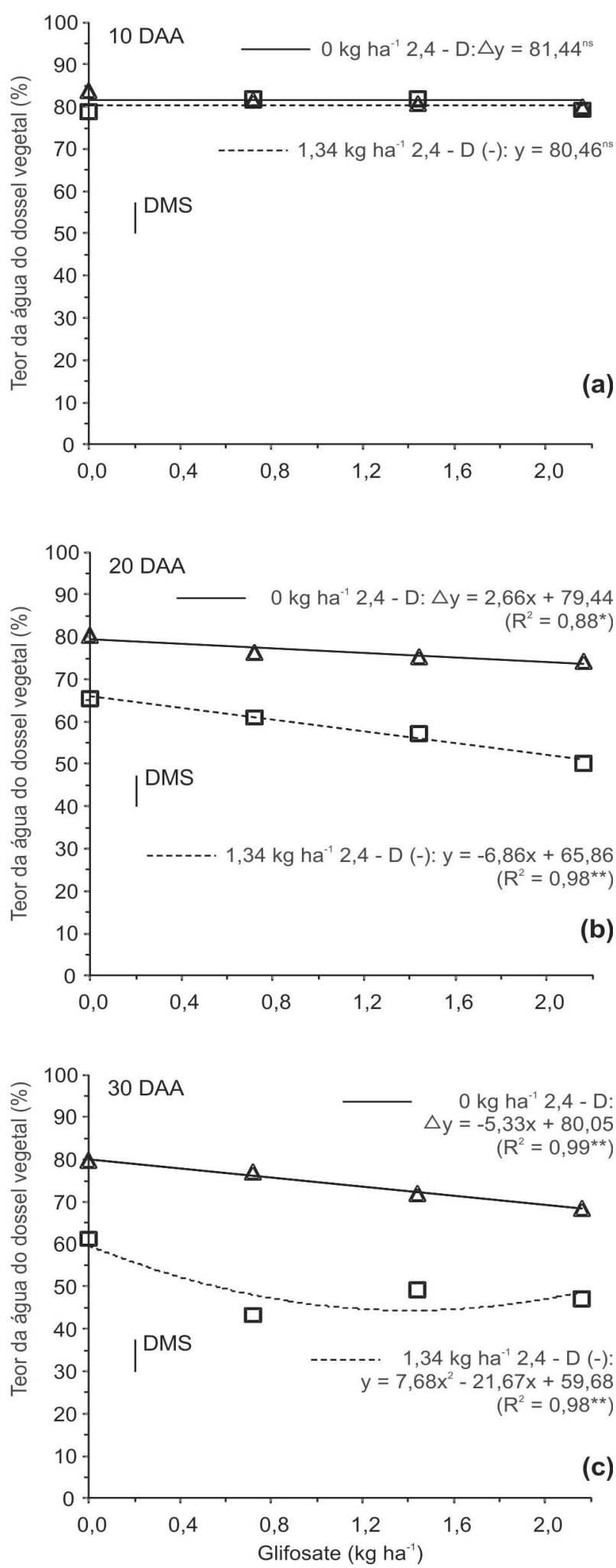

Figura 1. Teor de água do dossel da mamona, cultivar AL Guarany 2002, em lavoura de safrinha no SPD, em razão da combinação de doses de 2,4-D e de glifosate na dessecação em pré-colheita por ocasião da maturação dos cachos terciários, aos 10 (a), 20 (b) e 30 (c) dias após a aplicação dos herbicidas (DAA), em Rancharia-SP. DMS: Diferença mínima significativa pelo teste Tukey a $5 \%$ de probabilidade. ${ }^{*}$ e $* *$ significativos a 1 e $5 \%$ de probabilidade, respectivamente. ns: não significativo. CV (parcela) $=6,90 \% ; \mathrm{CV}($ subparcela $)=11,08 \%$. oleaginosa é extremamente sensível ao 2,4-D. A dessecação feita somente com 2,4-D proporcionou, aos 20 DAA, redução no teor de água das plantas de $79 \%$ (testemunha) para $66 \%$, e aos 30 DAA, houve redução de $80 \%$ para $60 \%$ (Figuras 1-b e 1-c).

De acordo com a equação quadrática apresentada na Figura 1-c, para a mistura de herbicidas aos 30 DAA, a máxima dessecação constatada no presente trabalho foi alcançada com $1,34 \mathrm{~kg} \mathrm{ha}^{-1}$ de 2,4-D mais $1,42 \mathrm{~kg} \mathrm{ha}^{-1} \mathrm{de}$ glifosato, ou seja, houve significativa economia de glifosato quando utilizado em mistura com 2,4-D.

Trabalhos têm demonstrado que a associação de glifosato e 2,4-D proporciona controle superior para algumas espécies de plantas daninhas, principalmente latifoliadas, em relação a esses herbicidas aplicados isoladamente, e corroboram a hipótese de um possível efeito complementar entre ambos (Ramos \& Durigan, 1996; Santos et al., 2002).

Portanto, a mistura de 2,4-D e glifosato proporcionou maior eficiência de dessecação em pré-colheita da mamona, ou seja, essa mistura de herbicidas pode melhorar as condições de lavoura para as colheitadeiras. Esses resultados reforçam as observações feitas no trabalho de Vidal \& Fleck (1993), no qual foi verificado que o glifosato aplicado isoladamente não foi suficiente para a dessecação do girassol em pré-colheita, por causa do efeito pouco pronunciado principalmente sobre as estruturas reprodutivas, mesmo quando foi aplicado no estádio de maturação fisiológica dos grãos. Os autores também verificaram que o glifosato não antecipou a colheita do girassol.

No caso da mamona, não se discute apenas a vantagem da antecipação da colheita, mas sim a necessidade de levar a lavoura à senescência por ocasião da maturação dos cachos terciários, pois não há sincronia de maturação entre os diferentes cachos e há significativa rebrota das soqueiras após a colheita (Savy Filho, 2005). Portanto, em um contexto de rotação de culturas no SPD, como vem sendo preconizado para a mamona em lavoura de safrinha em regiões de inverno seco do Brasil Central, é primordial gerar tecnologia para a dessecação química em pré-colheita dessa oleaginosa.

Na Figura 2, é apresentado o efeito do paraquat na dessecação da mamona aos 30 DAA, em que houve significativa eficiência na desidratação do dossel vegetal por ocasião da maturação dos cachos terciários, com vistas à colheita mecanizada. O grau de desidratação apresentou resposta linear em razão do aumento da dose do paraquat, evidenciando que, provavelmente, por ser um herbicida de contato, a extensão de tecidos lesionados foi ampliada com o aumento da concentração do ingrediente ativo na calda de pulverização.

O teor de água do dossel vegetal da mamona foi reduzido de $79 \%$ para $61 \%$, aos 30 DAA, quando foi utilizada a 


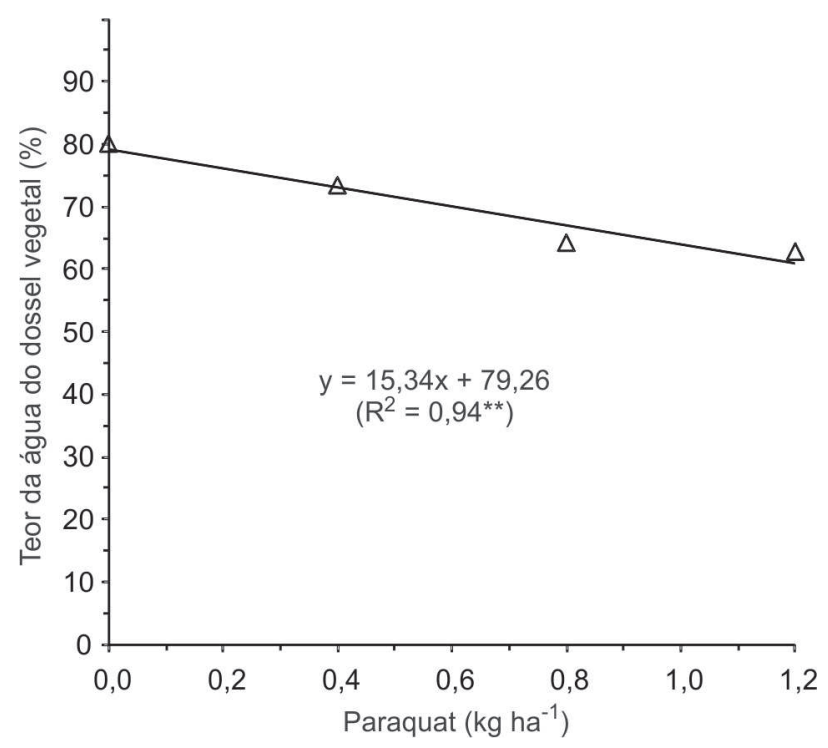

Figura 2. Teor de água do dossel da mamona, cultivar AL Guarany 2002, em lavoura de safrinha no SPD, em razão da dessecação em pré-colheita com doses de paraquat por ocasião da maturação dos cachos terciários, com avaliação feita aos 30 dias após a aplicação do herbicida, em Rancharia-SP. ** significativo a $1 \%$ de probabilidade. $\mathrm{CV}=9,51 \%$.

dose máxima de $1,2 \mathrm{~kg} \mathrm{ha}^{-1}$ de paraquat, em comparação ao tratamento testemunha (sem herbicida). Todavia, este resultado está aquém do obtido com a mistura de glifosato e 2,4-D (Figura 1-c), ou seja, o melhor desempenho foi para a associação de herbicidas, que reduziu o teor de água para 44\% no dossel vegetal aos $30 \mathrm{DAA}$, em comparação à testemunha (sem herbicida), de $80 \%$ de umidade.

\section{CONCLUSÕES}

A dessecação em pré-colheita da mamona, com a mistura de 2,4-D e glifosato, tem efeito somente a partir de 20 dias após a aplicação dos herbicidas.

O 2,4-D, utilizado isoladamente na dessecação em précolheita, tem expressiva capacidade de desidratação do dossel da mamona, porém, inferior à da mistura de 2,4-D mais glifosato.

A melhor dessecação química em pré-colheita é com a mistura de tanque com $1,34 \mathrm{~kg} \mathrm{ha}^{-1}$ de 2,4-D mais $1,42 \mathrm{~kg}$ ha-1 de glifosato, aos 30 dias após a aplicação.

A dose de $1,2 \mathrm{~kg} \mathrm{ha}^{-1}$ de paraquat reduz expressivamente o teor de água da mamona em pré-colheita, porém, com desempenho inferior ao da mistura de 2,4-D e glifosato.

\section{REFERÊNCIAS}

Almeida FS, Pineda-Aguilar A, Rodrigues BN (1991) Resíduos de paraquat em grão de soja quando usado como dessecante da cultura. Planta Daninha, 9:85-91.
Azevedo DMP, Severino LS (2006) Cultivo da mamona. Campina Grande: EMBRAPA-CNPA. (Embrapa Algodão. Sistemas de Produção, 4. 2.ed.) Disponível: http://sistemas de producao.cnptia.embrapa.br

Domingos P, Silva AA, Silva RF (1997) Qualidade da semente de feijão afetada por dessecantes, em quatro estádios de aplicação. Revista Brasileira de Sementes, 19:275-282.

Hess FD (1994) Mechanism of action of inhibitors of amino acid biosynthesis. In: Herbicide action: an intensive course on the activity, selectivity, behavior, and fate of herbicides in plants and soil. West Lafayette, Purdue University, p. 344-365.

Raij, B van, Andrade, JC, Cantarella, H, Quaggio, JA (2001) Análise química para avaliação da fertilidade de solos tropicais. Campinas, Instituto Agronômico, 285 p.

Ramos HH \& Durigan JC (1996) Avaliação da eficiência da mistura pronta de glifosato $+2,4-\mathrm{D}$ no controle da Commelina virginica L. em citros. Planta Daninha, 14:33-41.

Rodrigues, BN \& Almeida, FS (2005) Guia de herbicidas. 5a ed. Londrina, edição dos autores, 591 p.

Roman ES, Rodrigues O, McCracken A (2001) Dessecação: uma tecnologia que reduz perdas na colheita de soja. Passo Fundo, Embrapa Trigo. (Embrapa Trigo. Comunicado Técnico, 60). Disponível: www.cnpt.embrapa.br

Santos IC, Ferreira FA, Silva AA, Miranda GV, Santos LDT (2002) Eficiência do 2,4-D aplicado isoladamente e em mistura com glifosato no controle da trapoeraba. Planta Daninha, 20:299309.

Savy Filho, A. Mamona: tecnologia agrícola. Campinas, EMOPI, 2005. 105 p.

Taiz L \& Zeiger E (2004) Fisiologia vegetal. 3a . ed. Porto Alegre, Artmed, 719 p.

Vidal RA \& Fleck NG (1993) Antecipação da colheita do girassol através da dessecação com herbicidas. Pesquisa Agropecuária Brasileira, 28:585-591. 